\title{
40 Years of Angioplasty in Zurich; we Keep Having Flashbacks to the First-in-Human Coronary Angioplasty!
}

\section{Nooraldaem Yousif and Robert Manka*}

Department of Cardiology, University Heart Center at University Hospital Zurich, Switzerland

*Corresponding author: Robert Manka, Interventional Cardiologist and Head of Cardiac MRI, University Hospital Zurich, Switzerland.
Received Date: July 10, 2019

Published Date: July 12, 2019

Keywords: Angioplasty; PTCA; NSTE-ACS; LAD

\section{Case Report}

78 years old gentleman diagnosed as non-ST-segment elevation acute coronary syndrome (NSTE-ACS). The Culprit lesion was a mid left anterior descending artery (LAD) stenosis (arrow A), a similar lesion to the first in-man coronary angioplasty which was performed at the same cardiac center (University Heart Center Zurich) (arrow
B) exactly the same day (arrow C) 40 years back $\left(16^{\text {th }}\right.$ September 1977) by Dr. Andreas R. Grüntzig! This time the lesion was treated with drug-eluting stent (arrow E) that considered a gold standard now. Another mind-blowing coincidence is that our patient was born in 1939 (arrow D), likewise Dr. Grüntzig and Mr. Bachman (the first angioplasty patient)! Figure.

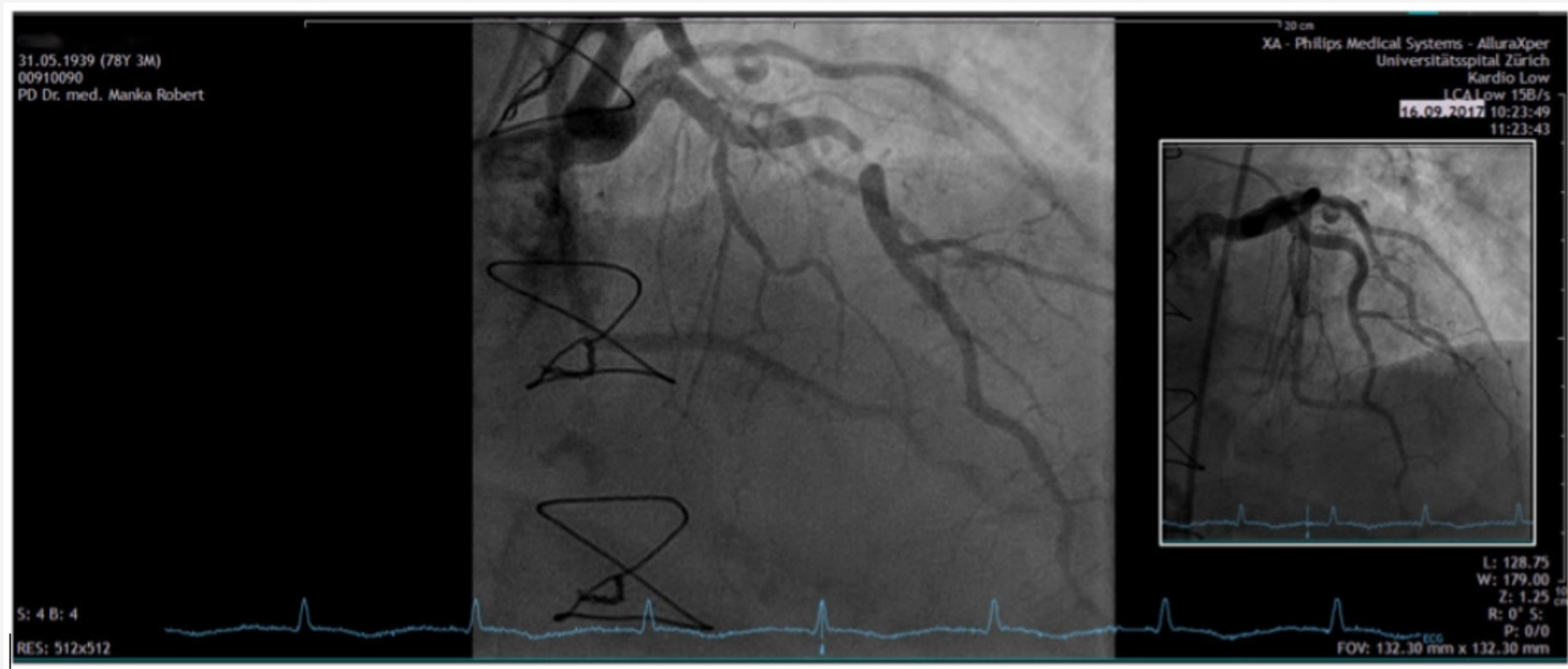

Figure 1 
Starting from the pioneering invention of Dr. Grüntzig in the 1970s towards today's state-of-the-art percutaneous coronary intervention (PCI) 40 years later, it has been a fascinating and is a still an ongoing evolutionary journey driven by courage, innovation and most importantly, persistence.

\section{Acknowledgement}

None.

\section{Conflict Of Interest}

No conflict of interest. 